\title{
Prevalence and Associated Factors of Self-Treatment among the Elderly-A Comparative Study between Empty and Non-Empty Nesters in Shandong, China
}

\author{
Zhaorong Gao ${ }^{1,2,3}$, Lingzhong $X u^{1,2,3, *}$, Wenzhe Qin ${ }^{1,2,3}$, Jiao Zhang ${ }^{1,2,3}$, Jinling Zhou ${ }^{4}$, \\ Fangfang $\mathrm{Hu}^{1,2,3}$ and Zhuang Hong ${ }^{1,2,3}$ \\ 1 School of Public Health, Cheeloo College of Medicine, Shandong University, Jinan 250012, China; \\ gaozr20160104@163.com (Z.G.); qinwenzhe09@163.com (W.Q.); zhangiiao5263@163.com (J.Z.); \\ hufang1218@yeah.net (F.H.); hongzhuang@mail.sdu.edu.cn (Z.H.) \\ 2 NHC Key Laboratory of Health Economics and Policy Research, Cheeloo College of Medicine, Shandong \\ University, Jinan 250012, China \\ 3 Shandong University Center for Health Economics Experiment and Public Policy Research, Shandong \\ University, Jinan 250012, China \\ 4 School of Medicine and Health Management, Cheeloo College of Medicine, Shandong University, \\ Jinan 250012, China; zhoujl@sdu.edu.cn \\ * Correspondence: 1zxu@sdu.edu.cn; Tel.: +86-0531-8838-2648
}

Received: 2 October 2020; Accepted: 23 October 2020; Published: 27 October 2020 updates

\begin{abstract}
Objectives: With an aging society in China, self-treatment now plays an important role in health care among older adults, but it can be problematic. This study aims to explore and compare the self-treatment behavior among empty and non-empty nesters. (2) Methods: Using a multi-stage stratified random cluster sampling method, a total of 4366 elderly people aged 60 and above from Shandong Province, China, were enrolled in this study. Data were collected through a structured questionnaire. Binary logistic regression was used to analyze the associated factors of self-treatment. (3) Results: The prevalence of self-treatment in empty nesters was significantly lower than that in non-empty ones $(74.0 \%$ vs. $83.3 \%$ ). Binary logistic regression analysis showed that higher educational level and poorer self-rated economic status were negatively associated with self-treatment in empty nesters, while unemployed and urban and rural residents' basic medical insurance were positively associated with self-treatment in non-empty ones. (4) Conclusions: The study indicated that empty nesters had lower likelihood of self-treatment than non-empty ones. Empty nesters with better socioeconomic status were more likely to use self-treatment; by contrast, non-empty nesters with relatively poorer socioeconomic status were more inclined to self-treatment. Targeted interventions should be developed to maximize the effectiveness of self-treatment and reduce health risks.
\end{abstract}

Keywords: self-treatment; associated factors; elderly; empty nesters; non-empty nesters

\section{Introduction}

The number of older population over 60 years was 250 million at the end of 2018, accounting for $17.9 \%$ of the total population in China. People above the age of 65 are projected to represent $26 \%$ of China's population by 2050 according to a report by the World Bank [1,2]. China is inevitably under the pressure of rapid aging. A major feature of China's population aging is the transition of elderly household patterns. Living with children is the typical Chinese traditional family pattern for older people [3]. But due to many factors, such as the one-child parents entering the elderly, the imbalance of economic development, the acceleration of urbanization, and population migration, the proportion of elders living alone or living with their spouse continues to rise. These elders are called "empty 
nesters" [3-6]. The estimated number of empty nester households will account for $90 \%$ of the elderly households by 2030 [7]. Due to the lack of affection and spiritual comfort from their children for a long period, the empty nest elderly might have a worse health status. With the increasing number of empty nest elderly, the demand on health services for the elderly has become a major challenge facing us.

When ill, individuals can seek professional health care, self-treat, or do nothing [8]. Self-treatment refers to treating oneself without professional help to alleviate an illness or a condition [9], including self-medication or massage, hot compress or other auxiliary therapy. The definition of self-treatment differs across different publications $[8,10,11]$. In developing countries, self-treatment is increasing rapidly. A systematic review showed that the prevalence of self-medication among the elderly varies from $20 \%$ to $60 \%$ in most studies [12]. An Iranian study indicated that $80 \%$ of patients chose self-treatment [11]. In China, the fourth National Health Service Survey released that $38.0 \%$ of patients did not go to see a doctor, of which $70.0 \%$ used self-treatment [13]. The data of the China Health and Retirement Longitudinal Study (CHARLS) in 2013 showed that the prevalence of self-treatment among the middle-aged and elderly patients with non-communicable chronic diseases was $64.04 \%$ [14]. Compared with other professional hospital-based healthcare approaches (inpatient and outpatient treatments), correct self-treatment can be helpful for both individuals and medical health system, such as convenience, accessibility, lower medical costs, complementing the health care system, and relieving the burden of limited medical services. It can effectively alleviate the problems of difficulty and expense when seeing a doctor $[8,15]$, and appropriate self-treatment can also avoid some unnecessary waste of medical resources [16]. But the negative effects of incorrect self-treatment cannot be ignored either. Irrational self-treatment, such as false self-diagnosis, drug abuse, missing optimal treatment, side effects or interaction with other drugs, can cause serious clinical consequences and unnecessary economic loss [15,17].

Older adults may be more likely to choose self-treatment due to the overall worse health status $[18,19]$. Previous studies have examined the potential determinates of self-treatment among the elderly. The decision to choose self-treatment involves a complex mechanism and is influenced by various factors, including individual, household, accessibility and medical insurance system factors $[10,20]$. Few studies, however, exist to date in China focusing on the roles of social changes and living arrangements in the use of self-treatment. Empty nesters may have a higher prevalence of self-treatment due to low socioeconomic status. Consequently, there is a clear need to evaluate nest status in the intensity of using self-treatment.

To extend the literature, the aims of this study are to identify the difference between empty and non-empty nesters in self-treatment behavior and comparatively evaluate the risk factors, respectively. This aims to provide a reference for formulating targeted interventions to improve self-treatment effectively.

\section{Materials and Methods}

\subsection{Data and Sample}

Our data were collected from the Survey of Shandong Elderly Family Health Service, which was conducted by Shandong University in 2017. This study was approved by the Academic Research Ethics Committee of Shandong University. We employed a stratified multi-stage random sampling method to select Weihai, Weifang, and Heze as survey locations based on the gross domestic product (high, media, low) and geographical location (east, middle, and west). After verbal informed consent was obtained from interviewees, 7088 elderly people aged 60 years or older were interviewed individually using a structured questionnaire. Of these, $18 \mathrm{did}$ not complete the survey. In total, 7070 individuals were included in the final sample. The detailed sampling methods have been described in a previously published article [21].

The current study focused on respondents who reported the presence of illness during the two-week period before they were interviewed with a sample of $n=4366$. 


\subsection{Dependent Variable}

In this article, self-treatment refers to "the scenario where a person takes medication (including over-the counter drugs or prescribed drug already in family) or other approaches, such as massage, hot compress or other auxiliary therapy, to cope with illness conditions without professional help" [9]. It was measured by a two-category qualitative question "Have you ever self-treatment during the two weeks?"

\subsection{Independent Variables}

Based on the location of residence of their adult children, we divided participants into two groups: empty nesters (living with their spouse, and their adult children had lived away from their village/community at least 6 months, or living alone, albeit with one or more adult children in the same village/community) and non-empty nesters (living with children, including those who live with one or more adult children).

Data on the demographic, socioeconomic, and health-related variables were collected using a self-designed questionnaire, including gender (male, female), age (60-69, 70-79, $\geq 80$ ), education (no schooling, primary school, junior school and above), employment (employed, retired, unemployed), marital status (single, couple), insurance (Urban and Rural Residents Basic Medical Insurance (URRBMI), Urban Employee Basic Medical Insurance (UEBMI), others, or none), self-rated economic status (wealthy, not wealthy but not worried about livelihood, not wealthy and worried about livelihood, or poor), self-rated health status (good, medium, bad), and chronic diseases (yes, no).

\subsection{Statistical Analysis}

All statistical analyses were performed using SPSS 24.0 (IBM Crop, Armonk, NY, USA). A chi-square test was used to compare the differences in basic characteristics between empty and non-empty nesters. A univariate logistic regression model and multivariate logistic regression model were used to explore the factors among empty and non-empty nest elderly respectively. Three binary logistic regression models were used to identify the difference in self-treatment between empty nesters and non-empty nesters. Model 1: univariate model. Model 2: binary logistic regression model, adjusted covariates for social-economic factors. Model 3: In addition to the factors in Model 2, health-related factors were included. Furthermore, a secondary analysis were performed to compare the differences in self-treatment among the 3 subtypes of "empty nesters". Association were determined by odds ratios (ORs) and 95\% confidence intervals (CIs). $p$-Values $<0.05$ were considered to be statistically significant.

\section{Results}

\subsection{Basic Characteristics}

Table 1 presents the basic information of subjects. The study included 4366 seniors with an average age of 70.01 years (standard deviation $(\mathrm{SD})=6.25$ ), of which $36.6 \%$ were men and $63.4 \%$ were women. 1592 (36.5\%) were empty nesters and 2774 (63.5\%) were non-empty ones. Most of them (74.8\%) had a qualification of primary school and below, more than $90 \%$ had one or more type of chronic diseases. Regarding self-treatment characteristics, the result showed that 3490 (79.9\%) elderly had self-treatment in two weeks and 876 (20.1\%) had not. Among these 3490 elderly who had self-treatment, 1178 (33.8\%) were empty nesters and $2312(66.2 \%)$ were non-empty ones. Non-empty nesters were more inclined to use self-treatment $(83.3 \%$ vs. $74.0 \%, p<0.001)$ than empty nesters. 
Table 1. Socio-demographic characteristics of the elderly in Shandong, China $(n=4366)$.

\begin{tabular}{|c|c|c|c|c|c|}
\hline \multirow{2}{*}{ Characteristics } & \multirow{2}{*}{$\begin{array}{l}\text { Total } \\
n(\%)\end{array}$} & \multirow{2}{*}{$\begin{array}{c}\text { Empty Nest } \\
n(\%)\end{array}$} & \multirow{2}{*}{$\begin{array}{c}\text { Non-Empty } \\
n(\%)\end{array}$} & \multirow{2}{*}{$x^{2}$} & \multirow{2}{*}{$p$-Value } \\
\hline & & & & & \\
\hline$n$ & $4366(100.0)$ & $1592(26.5)$ & $2774(63.5)$ & & \\
\hline Gender & & & & 1.001 & 0.317 \\
\hline Male & 1597 (36.6) & $567(35.6)$ & $1030(37.1)$ & & \\
\hline Female & $2769(63.4)$ & $1025(64.4)$ & $1744(62.9)$ & & \\
\hline Age & & & & 9.890 & 0.007 \\
\hline $60-69$ & $2205(50.5)$ & $756(47.5)$ & 1449 (52.2) & & \\
\hline $70-79$ & $1805(41.3)$ & $691(43.4)$ & $1114(40.2)$ & & \\
\hline$\geq 80$ & $356(8.2)$ & $145(9.1)$ & $211(7.6)$ & & \\
\hline Education & & & & 3.193 & 0.203 \\
\hline No schooling & $1480(33.9)$ & $521(32.7)$ & 959 (34.6) & & \\
\hline Primary school & 1787 (40.9) & $647(40.6)$ & $1140(41.1)$ & & \\
\hline Junior school and above & $1099(25.2)$ & $424(26.6)$ & $675(24.3)$ & & \\
\hline Employment & & & & 9.821 & 0.007 \\
\hline Employed & $1254(28.7)$ & $460(28.9)$ & $794(28.6)$ & & \\
\hline Retired & $902(20.7)$ & $290(18.2)$ & $612(22.1)$ & & \\
\hline Unemployed & $2210(50.6)$ & $842(52.9)$ & $1368(49.3)$ & & \\
\hline Marital status $^{\text {a }}$ & & & & 194.069 & $<0.001$ \\
\hline Single & $894(20.5)$ & $505(31.7)$ & $389(14.0)$ & & \\
\hline Couple & $3472(79.5)$ & $1087(68.3)$ & $2385(86.0)$ & & \\
\hline Insurance $b$ & & & & 6.997 & 0.072 \\
\hline URRBMI & $3449(79.0)$ & $1276(80.2)$ & $2173(78.3)$ & & \\
\hline UEBMI & $799(18.3)$ & $265(16.6)$ & $534(19.3)$ & & \\
\hline Others & $49(1.1)$ & $23(1.4)$ & $26(0.9)$ & & \\
\hline None & $69(1.6)$ & $28(1.8)$ & $41(1.5)$ & & \\
\hline Self-rated economic status ${ }^{c}$ & & & & 28.118 & $<0.001$ \\
\hline Q1 & $943(21.6)$ & $323(20.3)$ & $620(22.4)$ & & \\
\hline$\widehat{Q} 2$ & $3056(70.0)$ & $1090(68.5)$ & $1966(70.9)$ & & \\
\hline$\widehat{Q} 3$ & $332(7.6)$ & $165(10.4)$ & $167(6.0)$ & & \\
\hline Q4 & $35(0.8)$ & $14(0.9)$ & $21(0.8)$ & & \\
\hline Self-rated health status & & & & 6.374 & 0.041 \\
\hline Good & $1825(41.8)$ & $635(39.9)$ & $1190(42.9)$ & & \\
\hline Medium & $1456(33.3)$ & $529(33.2)$ & $927(33.4)$ & & \\
\hline Bad & $1085(24.9)$ & $428(26.9)$ & $657(23.7)$ & & \\
\hline Chronic diseases & & & & 5.847 & 0.016 \\
\hline Yes & 4058 (92.9) & $1460(91.7)$ & $2598(93.7)$ & & \\
\hline No & $308(7.1)$ & $132(8.3)$ & $176(6.3)$ & & \\
\hline Self-treatment & & & & 54.891 & $<0.001$ \\
\hline Yes & $3490(79.9)$ & $1178(74.0)$ & $2312(83.3)$ & & \\
\hline No & $876(20.1)$ & $414(26.0)$ & $462(16.7)$ & & \\
\hline
\end{tabular}

\subsection{Associations with Self-Treatment in Different Living Arrangements}

Table 2 reports the association of self-treatment and living arrangement. After adjusting covariates for social-economic factors and health related factors, model 3 showed that non-empty nesters were more likely to use self-treatment than the empty ones. ( $\mathrm{OR}=1.749,95 \% \mathrm{CI}=1.496-2.045, p<0.001)$. All of the three models indicated the difference in self-treatment among empty and non-empty nesters. In addition, there were no significant differences in self-treatment have been seen between the three subgroups of the empty nesters. 
Table 2. Association of self-treatment and living arrangement in Shandong, China.

\begin{tabular}{|c|c|c|c|}
\hline Characteristics & $\begin{array}{c}\text { Model } 1 \\
\text { OR }(95 \% \text { CI) }\end{array}$ & $\begin{array}{c}\text { Model } 2 \\
\text { OR (95\% CI) }\end{array}$ & $\begin{array}{c}\text { Model } 3 \\
\text { OR (95\% CI) }\end{array}$ \\
\hline \multicolumn{4}{|l|}{ Empty nest } \\
\hline Yes & 1.0 & 1.0 & 1.0 \\
\hline No & $1.759(1.514,2.043)^{* *}$ & $1.773(1.517,2.073)^{* *}$ & $1.749(1.496,2.045) * *$ \\
\hline \multicolumn{4}{|l|}{ Gender } \\
\hline Female & & 1.0 & 1.0 \\
\hline Male & & $0.931(0.788,1.100)$ & $0.920(0.779,1.085)$ \\
\hline \multicolumn{4}{|l|}{ Age } \\
\hline $60-69$ & & 1.0 & 1.0 \\
\hline $70-79$ & & $0.886(0.752,1.044)$ & $0.873(0.740,1.029)$ \\
\hline$\geq 80$ & & $1.050(0.763,1.445)$ & $1.058(0.769,1.457)$ \\
\hline \multicolumn{4}{|l|}{ Education } \\
\hline No schooling & & 1.0 & 1.0 \\
\hline Primary school & & $0.856(0.709,1.103)$ & $0.868(0.719,1.048)$ \\
\hline Junior school and above & & $0.724(0.575,0.911)$ * & $0.721(0.573,0.908)$ * \\
\hline \multicolumn{4}{|l|}{ Employment } \\
\hline Employed & & 1.0 & 1.0 \\
\hline Retired & & $0.964(0.707,1.313)$ & $0.944(0.692,1.288)$ \\
\hline Unemployed & & $1.157(0.961,1.393)$ & $1.141(0.947,1.375)$ \\
\hline \multicolumn{4}{|l|}{ Marital status $^{\text {a }}$} \\
\hline Couple & & 1.0 & 1.0 \\
\hline Single & & $1.169(0.953,1.433)$ & $1.145(0.935,1.402)$ \\
\hline \multicolumn{4}{|l|}{ Insurance $^{b}$} \\
\hline URRBMI & & 1.0 & 1.0 \\
\hline UEBMI & & $0.958(0.715,1.282)$ & $0.957(0.714,1.283)$ \\
\hline Others & & $0.394(0.208,0.744)$ * & $0.360(0.191,0.681)$ * \\
\hline None & & $1.234(0.613,2.483)$ & $1.210(0.598,2.448)$ \\
\hline \multicolumn{4}{|c|}{ Self-rated economic status ${ }^{c}$} \\
\hline Q1 & & 1.0 & 1.0 \\
\hline Q2 & & $0.746(0.604,0.922) *$ & $0.764(0.618,0.945)$ * \\
\hline$\widehat{\mathrm{Q} 3}$ & & $0.787(0.559,1.108)$ & $0.790(0.561,1.113)$ \\
\hline$\widehat{\mathrm{Q}} 4$ & & $0.744(0.326,1.695)$ & $0.719(0.316,1.636)$ \\
\hline \multicolumn{4}{|l|}{ Self-rated health status } \\
\hline Good & & & 1.0 \\
\hline Medium & & & $0.976(0.816,1.167)$ \\
\hline Bad & & & $0.816(0.671,0.991)$ * \\
\hline \multicolumn{4}{|l|}{ Chronic diseases } \\
\hline No & & & 1.0 \\
\hline Yes & & & $1.836(1.411,2.390)^{* *}$ \\
\hline
\end{tabular}

\subsection{Associated Factors of Self-Treatment among Empty Nesters}

Table 3 shows the factors associated with self-treatment behavior among empty nesters. Univariate analysis indicated that age, education, self-rated economic status, self-rated health status, and chronic diseases were significantly associated with self-treatment. Multivariate logistic analysis showed that poorer economic status $(p=0.041)$ and chronic diseases $(p=0.029)$ were positively associated with self-treatment. A higher education level $(p=0.001)$ was negatively associated with self-treatment. 
Table 3. Factors with self-treatment among empty nesters in Shandong. China. $(n=1592)$.

\begin{tabular}{|c|c|c|c|c|c|}
\hline Characteristics & $\frac{\text { Self-Treatment }}{\text { Yes }(\%)}$ & $\operatorname{COR}(95 \% \mathrm{CI})$ & $p$ & AOR $(95 \% C I)$ & $p$ \\
\hline Total & $1178(74.0)$ & & & & \\
\hline $\begin{array}{l}\text { Gender } \\
\text { Female } \\
\text { Male }\end{array}$ & $\begin{array}{l}774(75.5) \\
404(71.3)\end{array}$ & $\begin{array}{c}1.0 \\
0.804(0.638,1.013)\end{array}$ & 0.064 & & NA \\
\hline $\begin{array}{l}\text { Age } \\
\qquad \begin{array}{l}60-69 \\
70-79 \\
\geq 80\end{array}\end{array}$ & $\begin{array}{l}559(73.9) \\
499(72.2) \\
120(82.8) \\
\end{array}$ & $\begin{array}{c}1.0 \\
0.916(0.726,1.156) \\
1.692(1.067,2.681) \\
\end{array}$ & $\begin{array}{l}0.459 \\
0.025\end{array}$ & $\begin{array}{c}1.0 \\
0.809(0.635,1.031) \\
1.367(0.851,2.196) \\
\end{array}$ & $\begin{array}{l}0.087 \\
0.196 \\
\end{array}$ \\
\hline $\begin{array}{l}\text { Education } \\
\text { No schooling } \\
\text { Primary school } \\
\text { Junior school and } \\
\text { above }\end{array}$ & $\begin{array}{l}406(77.9) \\
472(73.0) \\
300(70.8)\end{array}$ & $\begin{array}{c}1.0 \\
0.764(0.583,1.001) \\
0.685(0.511,0.920)\end{array}$ & $\begin{array}{l}0.051 \\
0.012\end{array}$ & $\begin{array}{c}1.0 \\
0.743(0.563,0.981) \\
0.593(0.423,0.809)\end{array}$ & $\begin{array}{l}0.036 \\
0.001\end{array}$ \\
\hline $\begin{array}{l}\text { Employment } \\
\text { Employed } \\
\text { Retired } \\
\text { Unemployed }\end{array}$ & $\begin{array}{l}341(74.1) \\
215(74.1) \\
622(73.9)\end{array}$ & $\begin{array}{c}1.0 \\
1.000(0.715,1.399) \\
0.987(0.761,1.279)\end{array}$ & $\begin{array}{l}0.998 \\
0.919\end{array}$ & & NA \\
\hline $\begin{array}{l}\text { Marital status a } \\
\text { Couple } \\
\text { Single }\end{array}$ & $\begin{array}{l}791(72.8) \\
387(76.6)\end{array}$ & $\begin{array}{c}1.0 \\
1.227(0.960,1.569)\end{array}$ & 0.102 & & NA \\
\hline $\begin{array}{c}\text { Insurance }^{\mathrm{b}} \\
\text { URRBMI } \\
\text { UEBMI } \\
\text { Others } \\
\text { None }\end{array}$ & $\begin{array}{l}945(74.1) \\
197(74.3) \\
14(60.9) \\
22(78.6)\end{array}$ & $\begin{array}{c}1.0 \\
1.015(0.750,1.374) \\
0.537(0.222,1.297) \\
1.266(0.493,3.253)\end{array}$ & $\begin{array}{l}0.925 \\
0.167 \\
0.625\end{array}$ & & NA \\
\hline
\end{tabular}

\begin{tabular}{|c|c|c|c|c|c|}
\hline \multicolumn{6}{|c|}{$\begin{array}{l}\text { Self-rated economic } \\
\text { status }{ }^{c}\end{array}$} \\
\hline Q1 & $264(81.7)$ & 1.0 & & 1.0 & \\
\hline Q2 & $798(73.2)$ & $0.611(0.447,0.835)$ & 0.002 & $0.588(0.424,0.815)$ & 0.001 \\
\hline Q3 & $109(66.1)$ & $0.435(0.283,0.668)$ & $<0.001$ & $0.487(0.306,0.776)$ & 0.002 \\
\hline$\widehat{Q} 4$ & $7(50.0)$ & $0.223(0.076,0.661)$ & 0.007 & $0.297(0.093,0.952)$ & 0.041 \\
\hline \multicolumn{6}{|c|}{ Self-rated health status } \\
\hline Good & $490(77.2)$ & 1.0 & & 1.0 & \\
\hline Medium & $392(74.1)$ & $0.847(0.647,1.108)$ & 0.225 & $0.866(0.658,1.140)$ & 0.306 \\
\hline Bad & $296(69.2)$ & $0.664(0.503,0.875)$ & 0.004 & $0.776(0.577,1.043)$ & 0.093 \\
\hline \multicolumn{6}{|c|}{ Chronic diseases } \\
\hline No & $88(66.7)$ & 1.0 & & 1.0 & \\
\hline Yes & $1090(74.7)$ & $1.473(1.007,2.155)$ & 0.046 & $1.548(1.045,2.294)$ & 0.029 \\
\hline
\end{tabular}

\subsection{Associated Factors of Self-Treatment among Non-Empty Nesters}

As shown in Table 4, univariate analysis indicated that employment, insurance and chronic diseases were related to self-treatment in non-empty nesters. Multivariate logistic analysis showed that being unemployed $(p=0.001)$, and chronic diseases $(p<0.001)$ were increased the likelihood of self-treatment. Elderly with other types of insurance $(p=0.015)$ were less likely to use self-treatment. 
Table 4. Factors with self-treatment among non-empty nesters in Shandong. China. $(n=2774)$.

\begin{tabular}{|c|c|c|c|c|c|}
\hline Characteristics & $\begin{array}{c}\text { Self-Treatment } \\
\text { Yes }(\%)\end{array}$ & $\operatorname{COR}(95 \% \mathrm{CI})$ & $p$ & AOR $(95 \% C I)$ & $p$ \\
\hline Total & 2312 (83.3) & & & & \\
\hline $\begin{array}{l}\text { Gender } \\
\text { Female } \\
\text { Male }\end{array}$ & $\begin{array}{l}1471(84.3) \\
841(81.7)\end{array}$ & $\begin{array}{c}1.0 \\
0.826(0.673,1.013)\end{array}$ & 0.066 & & NA \\
\hline $\begin{array}{l}\text { Age } \\
\qquad 60-69 \\
70-79 \\
\geq 80\end{array}$ & $\begin{array}{l}1205(83.2) \\
930(83.5) \\
177(83.9)\end{array}$ & $\begin{array}{c}1.0 \\
1.023(0.830,1.262) \\
1.054(0.712,1.560)\end{array}$ & $\begin{array}{l}0.828 \\
0.792\end{array}$ & & NA \\
\hline $\begin{array}{l}\text { Educational level } \\
\text { No schooling } \\
\text { Primary school } \\
\text { junior school and } \\
\text { above }\end{array}$ & $\begin{array}{l}811(84.6) \\
954(83.7) \\
547(81.0)\end{array}$ & $\begin{array}{c}1.0 \\
0.936(0.740,1.184) \\
0.780(0.601,1.012)\end{array}$ & $\begin{array}{l}0.582 \\
0.061\end{array}$ & & NA \\
\hline $\begin{array}{l}\text { Employment } \\
\text { Employed } \\
\text { Retired } \\
\text { Unemployed }\end{array}$ & $\begin{array}{c}638(80.4) \\
500(81.7) \\
1174(85.5)\end{array}$ & $\begin{array}{c}1.0 \\
1.092(0.834,1.429) \\
1.480(1.174,1.866)\end{array}$ & $\begin{array}{l}0.524 \\
0.001\end{array}$ & $\begin{array}{c}1.0 \\
1.190(0.784,1.808) \\
1.542(1.208,1.969)\end{array}$ & $\begin{array}{l}0.414 \\
0.001\end{array}$ \\
\hline $\begin{array}{l}\text { Marital status }{ }^{\text {a }} \\
\text { Couple } \\
\text { Single }\end{array}$ & $\begin{array}{l}1977(82.9) \\
335(86.1)\end{array}$ & $\begin{array}{c}1.0 \\
1.280(0.942,1.740)\end{array}$ & 0.114 & 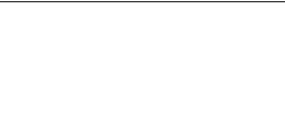 & NA \\
\hline $\begin{array}{c}\text { Insurance }{ }^{b} \\
\text { URRBMI } \\
\text { UEBMI } \\
\text { Others } \\
\text { None }\end{array}$ & $\begin{array}{l}1818(83.7) \\
441(82.6) \\
17(65.4) \\
36(87.7)\end{array}$ & $\begin{array}{c}1.0 \\
0.926(0.720,1.190) \\
0.398(0.172,0.921) \\
1.518(0.580,3.973)\end{array}$ & $\begin{array}{l}0.548 \\
0.031 \\
0.395\end{array}$ & $\begin{array}{c}1.0 \\
0.894(0.605,1.321) \\
0.344(0.145,0.814) \\
1.286(0.479,3.450)\end{array}$ & $\begin{array}{l}0.572 \\
0.015 \\
0.618\end{array}$ \\
\hline $\begin{array}{l}\text { Self-rated economic } \\
\text { status }^{c} \\
\text { Q1 } \\
\text { Q2 } \\
\text { Q3 } \\
\text { Q4 }\end{array}$ & $\begin{array}{c}515(83.1) \\
1631(83.0) \\
147(88.0) \\
19(90.5)\end{array}$ & $\begin{array}{c}1.0 \\
0.993(0.780,1.263) \\
1.499(0.898,2.501) \\
1.937(0.444,8.441)\end{array}$ & $\begin{array}{l}0.952 \\
0.122 \\
0.379\end{array}$ & & NA \\
\hline $\begin{array}{l}\text { Self-rated health status } \\
\text { Good } \\
\text { Medium } \\
\text { Bad }\end{array}$ & $\begin{array}{l}989(83.1) \\
782(84.4) \\
541(82.3)\end{array}$ & $\begin{array}{c}1.0 \\
1.096(0.868,1.384) \\
0.948(0.737,1.219)\end{array}$ & $\begin{array}{l}0.441 \\
0.676\end{array}$ & & NA \\
\hline $\begin{array}{l}\text { Chronic diseases } \\
\text { No } \\
\text { Yes }\end{array}$ & $\begin{array}{l}127(72.2) \\
2185(84.1)\end{array}$ & $\begin{array}{c}1.0 \\
2.041(1.444,2.885)\end{array}$ & $<0.001$ & $\begin{array}{c}1.0 \\
2.038(1.436,2.892)\end{array}$ & $<0.001$ \\
\hline
\end{tabular}

\section{Discussion}

The study showed that the prevalence of self-treatment among the elderly who reported the presence of illness during the two-week period before they were interviewed in Shandong, China, was $79.9 \%$, which was higher than other similar studies [19,22]. It is difficult to compare with other studies due to the use of different definitions of self-treatment in each study. With the development of the economy and society, the access channels for health information is becoming more and more diversified, which plays a certain role in promoting self-treatment behavior. 
Our results showed that the prevalence of self-treatment in empty nesters was lower than that in non-empty ones $(74.0 \%$ vs. $83.3 \%)$, and the difference was significant after adjusting variables for social-economic and health-related factors. It is inconsistent with our hypothesis that the empty nesters may have a higher prevalence of self-treatment due to the poorer socioeconomic status. The possible explanation may be that China has improved the accessibility and equality for health services effectively in the past few years. A previous study [3] conducted in Shandong, China in 2011 showed that the empty nesters have a higher non-use rate of healthcare services than non-empty ones due to the fact that the higher demand for health services cannot be met equally, but another study conducted in Sinan county, China, in 2018 was inconsistent with it, which found that the empty nesters were less likely to choose self-treatment. After the 'healthy China 2030' plan released by the central government in 2016, a series of health poverty alleviation projects were implemented with the goal of strengthening financial risk protection against illness for the financially backward population [23-25]. A study indicated that more than 4.2 million poor patients with serious or chronic diseases have been treated due to the health poverty alleviation project [26]. Another important explanation for non-empty nesters having a higher prevalence of self-treatment than empty ones is that the family caregivers are often equipped with some knowledge and common skills of healthcare tasks due to the increased frailty of the elderly, and the non-empty nesters would usually deal with their discomfort with the support of their adult children [20].The results suggests that it is important to strengthen health education for elderly and family caregivers to make them understand the risks of improper self-treatment.

However, our separate analysis of empty and non-empty nesters showed that the effect of the socio-economic status on the behavior of self-treatment is significant for the empty nesters, but is not for the non-empty nesters. Among the empty nesters, the elderly who reported better economic status were more likely to use self-treatment. On the one hand, our view is that the targeted health poverty alleviation policy effectively improved the utilization of health services for the poorer population [27-29]. On the other hand, the possible explanation is that the elderly in poverty may have difficulty self-purchasing drugs with out-of-pocket money, which cannot be covered by medical insurance [20], and the elderly with higher affordability have more access to medical resources outside hospitals. In addition, education was negatively associated with self-treatment in empty nesters, educational level is related to the ability to access health information, elderly who with higher education usually have higher health literacy. However, even though our results showed a statistical significance between education and behavior, the clinical significance of the self-treatment rate of three groups of education level in Table 3,77.9\% in the least education and $70.8 \%$ in the most education, does not seem too impressive. We will further explore the relationship between education and self-treatment in the following research.

Regarding the non-empty nesters, there was no significant difference in using self-treatment among the elderly with different economic status. Except for the fact that empty nest elders are given more attention and social support than non-empty nesters due to their special physical and psychological needs, the health poverty alleviation project may be more significant in improving their health service utilization [30-34]. Furthermore, according to the need theory, the basic material needs must be fulfilled, and then additional economic resources may affect subjective behaviors with respect to non-material needs, but to a lesser degree $[35,36]$. This study used self-reported economic status, rather than objective income measures. It is subjective and can measure a person's evaluation of their own socio-economic conditions more accurately that those less affected by the external factors. Compared with empty nesters, non-empty nesters have a higher demand for economic satisfaction and less additional economic resources to affect their medical behavior. However, insurance and employment were associated with self-treatment among non-empty nesters. URRBMI increased the likelihood of self-treatment compared with other types of commercial insurance. In addition, being unemployed was a predictor to self-treatment also. The findings suggest that after meeting basic material needs, relative income levels are negatively correlated with self-treatment among non-empty nesters. 
Consistent with other similar studies $[8,19,37,38]$, our results showed that chronic diseases was one common predictor of self-treatment among both empty and non-empty nesters. It should be noted that our study population include the elderly who had one or more chronic diseases but in a relatively stable status and need long-term medication, which may cause a higher prevalence of self-treatment among the elderly with chronic diseases.

There are some limitations in this study. First, this is a cross-sectional study and, therefore, the resulting factors associated with self-treatment behavior cannot determine causality. Second, the data were self-reported, and there might be a possible recall bias for most questionnaire data. Third, as for the definition of self-treatment, we only explained to the respondents before the survey that self-treatment refers to "the scenario where a person takes medication (including over-the counter drugs or prescribed drug already in family) or other approaches, such as massage, hot compress or other auxiliary therapy, to cope with illness conditions without professional help", and it cannot be defined in detail. For example, it is not clear that whether it was self-treatment when they did exercises to relieve neck pain even though the exercises were recommended by a physical therapist. Therefore, this situation may cause potential additional biases. Finally, there may be more confounding factors than those available for consideration in this study. In addition, our study did not involve the self-treatment rate of single diseases, and the next step of our research can explore the diseases with the highest prevalence of self-treatment and find the priority management of diseases.

\section{Conclusions}

The prevalence of self-treatment among the elderly in Shandong, China, was 79.9\%. Non-empty nest elderly had a higher prevalence of self-treatment than empty nesters. Our result showed that empty nesters with better socioeconomic status were more likely to use self-treatment, while non-empty nesters with relatively poorer socioeconomic status were more inclined to self-treatment. The findings from our study could provide the government with some information about the use of self-treatment among empty and non-empty nesters. Interventions targeting identified at-risk subgroups should be developed to maximize the effectiveness of self-treatment and reduce health risks.

Author Contributions: All authors made substantial contributions to this study. Z.G. analyzed the data and wrote the manuscript. L.X. provided important guidance on the writing. W.Q. and, J.Z. (Jiao Zhang) give many valuable comments on the draft. J.Z. (Jinling Zhou) designed and supervised the questionnaire. F.H. and, Z.H. contributed significantly to the interpretation of the results. All authors have read and agreed to the published version of the manuscript.

Funding: The study was supported by two grant of National Natural Science Foundation of China (grant numbers: 71673169 and 71974118).

Acknowledgments: The authors thank all the participants for their cooperation.

Conflicts of Interest: The authors declare that they have no competing interests.

\section{References}

1. Xu, J.; Kong, L. Focus on chronic diseases and promote healthy ageing. Chin. J. Prev. Control Chronic Dis. 2020, 28, 641-644.

2. IBRD.IDA. Options for Aged Care in China: Building an Efficient and Sustainable Aged Care System (English). Available online: https://www.shihang.org/zh/news/press-release/2018/12/13/world-bank-reportoffers-options-for-elderly-care-in-china (accessed on 13 December 2018).

3. Zhou, C.; Ji, C.; Chu, J.; Medina, A.; Li, C.; Jiang, S.; Zheng, W.; Liu, J.; Rozelle, S. Non-use of health care service among empty-nest elderly in Shandong, China: A cross-sectional study. BMC Health Serv. Res. 2015, 15, 294. [CrossRef] [PubMed]

4. Duan, D.; Dong, Y.; Zhang, H.; Zhao, Y.; Diao, Y.; Cui, Y.; Wang, J.; Chai, Q.; Liu, Z. Empty-nest-related psychological distress is associated with progression of brain white matter lesions and cognitive impairment in the elderly. Sci. Rep. 2017, 7, 43816. [CrossRef] [PubMed] 
5. Wang, Z.Q.; Shu, D.F.; Dong, B.R.; Luo, L.; Hao, Q.K. Anxiety disorders and its risk factors among the Sichuan empty-nest older adults: A cross-sectional study. Arch. Gerontol. Geriatr. 2013, 56, 298-302. [CrossRef]

6. Cheng, P.; Jin, Y.; Sun, H.M.; Tang, Z.H.; Zhang, C.; Chen, Y.J.; Zhang, Q.; Zhang, Q.H.; Huang, F. Disparities in prevalence and risk indicators of loneliness between rural empty nest and non-empty nest older adults in Chizhou, China. Geriatr. Gerontol. Int. 2015, 15, 356-364. [CrossRef]

7. Zhang, C.; Hou, L.; Zheng, X.; Zhu, R.; Zhao, H.; Lu, J.; Cheng, J.; Yang, X.Y.; Yang, T. Risk factors of mental disorders among empty and non-empty nesters in Shanxi, China: A cross-sectional study. Health Qual. Life Outcomes 2019, 17, 18. [CrossRef]

8. Yuefeng, L.; Keqin, R.; Xiaowei, R. Use of and factors associated with self-treatment in China. BMC Public Health 2012, 12, 995. [CrossRef]

9. Zhao, Y.; Ma, S. Observations on the Prevalence, Characteristics, and Effects of Self-Treatment. Front. Public Health 2016, 4, 69. [CrossRef]

10. Jiang, Y.; Wang, Y.; Li, Y.; Wang, X.; Ma, C.; Ma, S. Prevalence, characteristics, and cost of self-treatment in the middle-aged and elderly: Observations from Henan, China. Public Health 2015, 129, 597-600. [CrossRef]

11. Alavi, N.M.; Alami, L.; Taefi, S.; Gharabagh, G.S. Factor analysis of self-treatment in diabetes mellitus: A cross-sectional study. BMC Public Health 2011, 11, 761. [CrossRef]

12. Jerez-Roig, J.; Medeiros, L.F.; Silva, V.A.; Bezerra, C.L.; Cavalcante, L.A.; Piuvezam, G.; Souza, D.L. Prevalence of self-medication and associated factors in an elderly population: A systematic review. Drugs Aging 2014, 31, 883-896. [CrossRef] [PubMed]

13. Lu, J.; Hao, Y.; Wu, Q.; Gao, X. The Prevalence, Influencing Factors and Safety Issues of Self-treatment. Chin. Prim. Health Care 2012, 2404, 5-7. (In Chinese)

14. Yang, J.; Li, Y.; Chen, X.; Gao, J.; Feng, Z. Economic Burden among Middle-aged and Elderly Patients with Chronic Diseases. Chin. Health Econ. 2019, 38, 71-73. (In Chinese)

15. Wang, R.; Ma, C.; Jiang, K.; Li, M.; Ma, S. Descriptions of self-treatment for the middle-aged and elderly in Shanxi, China. PLoS ONE 2018, 13, e0198554. [CrossRef] [PubMed]

16. Yousef, A.M.; Al-Bakri, A.G.; Bustanji, Y.; Wazaify, M. Self-medication patterns in Amman, Jordan. Pharm. World Sci. 2008, 30, 24-30. [CrossRef] [PubMed]

17. Neoh, C.F.; Long, C.M.; Lim, S.M.; Ramasamy, K.; Shahar, S.; Majeed, A.B.A. Medication use and adherence among multi-ethnic community-dwelling older adults in Malaysia. Geriatr. Gerontol. Int. 2017, 17, 1214-1220. [CrossRef] [PubMed]

18. Zhang, C.; Xue, Y.; Zhao, H.; Zheng, X.; Zhu, R.; Du, Y.; Zheng, J.; Yang, T. Prevalence and related influencing factors of depressive symptoms among empty-nest elderly in Shanxi, China. J. Affect. Disord. 2019, 245, 750-756. [CrossRef]

19. Zhang, X.; Zheng, Z.; Gong, X. Study on the Current Status and Its Influencing Factors of Self-treatment in the Middle-aged and Elderly Population in China. Chin. Prim. Health Care 2019, 33, 36-38. (In Chinese)

20. Xu, W.; Li, Z.; Pan, Z.; He, R.; Zhang, L. Prevalence and associated factors of self-treatment behaviour among different elder subgroups in rural China: A cross-sectional study. Int. J. Equity Health 2020, 19. [CrossRef]

21. Zhang, J.; Xu, L.; Li, J.; Sun, L.; Ding, G.; Qin, W.; Wang, Q.; Zhu, J.; Yu, Z.; Xie, S. Loneliness and Health Service Utilization among the Rural Elderly in Shandong, China: A Cross-Sectional Study. Int. J. Environ. Res. Public Health 2018, 15, 1468. [CrossRef]

22. Liu, M.; Jing, M.; Li, X.; Niu, Q.; Mu, L.; Chen, B. A study on the medical behavior of Kazakh chronic disease patients in rural Yili, Xinjiang. J. Shihezi Univ. 2016, 34, 334. (In Chinese)

23. Wang, H.Y.; Shi, L.; Han, X.Y.; Zhang, J.C.; Ma, Y.S.; Yang, X.; Liu, M.; Fan, L.H.; Lou, F.G. Factors associated with contracted services of Chinese family doctors from the perspective of medical staff and consumers: A cross-sectional study. BMC Health Serv. Res. 2019, 19, 9. [CrossRef] [PubMed]

24. Wang, Y.P.; Zhou, X.N. The year 2020, a milestone in breaking the vicious cycle of poverty and illness in China. Infect. Dis. Poverty 2020, 9, 11. [CrossRef] [PubMed]

25. Li, Z.Y.; Liu, X.Y.; Zhang, Z.G.; Huang, L.; Zhong, Q.; He, R.L.; Chen, P.; Li, A.L.; Liang, J.; Lei, J.B. Epidemiology of Hypertension in a Typical State-Level Poverty-Stricken County in China and Evaluation of a Whole Population Health Prevention Project Intervention. Int. J. Hypertens. 2019, 2019, 10. [CrossRef] [PubMed]

26. Chen, C.; Pan, J. The effect of the health poverty alleviation project on financial risk protection for rural residents: Evidence from Chishui City, China. Int. J. Equity Health 2019, 18, 79. [CrossRef] 
27. Quynh Nguyen, T.; Tran, T.T.T.; Le, T.V.; Quyen, T.T.B.; Trinh, V.H.; Tran, H.B. Prevalence of Self-Treatment Practice and Related Factors Among Workers Aged 15 to 60 Years in Chi Linh Town, Hai Duong Province, Vietnam. Asia Pac. J. Public Health 2017, 29, 62S-71S. [CrossRef]

28. Wang, Y.; Jiang, Y.; Li, Y.; Wang, X.; Ma, C.; Ma, S. Health insurance utilization and its impact: Observations from the middle-aged and elderly in China. PLoS ONE 2013, 8, e80978. [CrossRef]

29. Jiang, Y.; Wang, Y.; Zhang, L.; Li, Y.; Wang, X.J.; Ma, S.G. Access to Healthcare and Medical Expenditure for the Middle-Aged and Elderly: Observations from China. PLoS ONE 2013, 8, 10. [CrossRef]

30. Wang, J.; Zhao, X. Empty nest syndrome in China. Int. J. Soc. Psychiatry 2012, 58, 110. [CrossRef]

31. Wang, G.; Hu, M.; Xiao, S.Y.; Zhou, L. Loneliness and depression among rural empty-nest elderly adults in Liuyang, China: A cross-sectional study. BMJ Open 2017, 7, e016091. [CrossRef]

32. Su, H.; Cao, J.; Zhou, Y.; Wang, L.; Xing, L. The mediating effect of coping style on personality and mental health among elderly Chinese empty-nester: A cross-sectional study. Arch. Gerontol. Geriatr. 2018, 75, 197-201. [CrossRef] [PubMed]

33. Bautista, L.E.; Vera-Cala, L.M.; Colombo, C.; Smith, P. Symptoms of depression and anxiety and adherence to antihypertensive medication. Am. J. Hypertens. 2012, 25, 505-511. [CrossRef] [PubMed]

34. Nie, J.X.; Wang, L.; Tracy, C.S.; Moineddin, R.; Upshur, R.E. Health care service utilization among the elderly: Findings from the Study to Understand the Chronic Condition Experience of the Elderly and the Disabled (SUCCEED project). J. Eval. Clin. Pract. 2008, 14, 1044-1049. [CrossRef] [PubMed]

35. Hsu, H.C. Trajectory of Life Satisfaction and its Relationship with Subjective Economic Status and Successful Aging. Soc. Indic. Res. 2010, 99, 455-468. [CrossRef]

36. Diener, E.; Sandvik, E.; Seidlitz, L.; Diener, M. The relationship between income and subjective well-being-relative or absolute. Soc. Indic. Res. 1993, 28, 195-223. [CrossRef]

37. Luo, J.; Zhang, X.; Jin, C.; Wang, D. Inequality of access to health care among the urban elderly in northwestern China. Health Policy 2009, 93, 111-117. [CrossRef]

38. Jiang, W.; Xu, X.; Tang, S.; Xu, L.; Zhang, Y.; Elbers, C.; Cobelens, F.; Yan, L. Inequity in healthcare needs, health service use and financial burden of medical expenditures in China: Results from a consecutive household monitoring study in Jiangsu Province. BMC Health Serv. Res. 2019, 19, 966. [CrossRef]

Publisher's Note: MDPI stays neutral with regard to jurisdictional claims in published maps and institutional affiliations.

(C) 2020 by the authors. Licensee MDPI, Basel, Switzerland. This article is an open access article distributed under the terms and conditions of the Creative Commons Attribution (CC BY) license (http://creativecommons.org/licenses/by/4.0/). 